\title{
Rethinking behaviour change: a dynamic approach in social marketing
}

\author{
Journal of Social Marketing [in press]
}

\author{
Patricia David \\ Social Marketing@ Griffith, Griffith University \\ Sharyn Rundle-Thiele \\ Social Marketing @ Griffith, Griffith University
}

\begin{abstract}
Purpose - While awareness of social, health and environmental consequences of our collective action are growing; additional efforts are required to deliver the changes needed to affect the greater good. A review of the literature indicates that research efforts may be misdirected. Drawing from empirical data where a total of 161 caregivers reported changes in their child's walking behaviour following a month long social marketing program, this paper illustrates differences between behaviour and behaviour change.
\end{abstract}

Design/methodology/approach - Data analyses involved use of multiple linear regression on static followed by dynamic measures of behaviour and behavioural change and their respective determinants. The static model used variables reported by caregivers after program participation, while the dynamic measures used change scores for all variables reported $(\mathrm{T} 2-\mathrm{T} 1)$.

Findings - Results from the static model showed that only intentions and barriers explained behaviour at Time point 2. In contrast, findings from the dynamic data analysis indicated that a change in injunctive norms (important others' approval of the child walking to school) explained a change in walking to and from school behaviour. Taken together, the results of the current study suggest research attention needs to be directed towards dynamic methodologies to re-centre research attention on behavioural change and not behaviour, which dominates current practice.

Originality/value - This paper offers a foundational step to support the research community to redirect research efforts from understanding behaviour to focussing research design and theoretical development on behavioural change. Theories of behaviour change are needed to affect the greater good.

Keywords: Behaviour, Behaviour change, Static, Dynamic, Theory

The Victorian Health Promotion Foundation (VicHealth) funded and supported this research. The funders played no role in study design, collection, analysis, interpretation of data, or in the decision to submit the paper for publication. They accept no responsibility for contents. 


\section{Background}

While the outcomes derived from successful social marketing are behavioural, environmental or policy changes; the dominant conceptual and methodological focus centres research attention on behaviour and not behavioural change. Given the aim of social marketing is to deliver behavioural change it is surprising that so little research attention is focussed on behavioural change. Social marketing has been applied in a wide variety of contexts including smoking cessation (Almestahiri et al., 2017), alcohol consumption (Kubacki et al., 2015), increasing healthy eating (Carins and Rundle-Thiele, 2014), food waste (David et al., 2019), increasing physical activity (Fujihira et al., 2017), and many more.

The present study is situated in the context of physical activity, more specifically increasing children's active school travel. A WHO report (2010) shows that an insufficient amount of physical activity is responsible for 3.2 million deaths globally every year (World Health Organization, 2010). Research also indicates that an increase in physical activity can prevent health issues (Bull and Bauman, 2011). Increasing children's active school travel can be a cost effective way to prevent children's obesity (Pang et al., 2017). Hence, extending understanding beyond factors explaining current walking to and from school behaviour to the determinants that explain or predict observed increases in walking to and from school (behaviour change) is crucial to understand how social marketing intervention effectiveness can be increased.

From its first conception to the present day, social marketing has and continues to evolve. In the first two decades, social marketing was largely based on the application of promotion to influence change (see examples in Maibach, 1993, Lock and Kaner, 2000, Van Rossem and Meekers, 2000, Samuels, 1993). In the following years, a shift from initial social marketing conceptualisation was evident, with a behaviour focus gaining prominence in the field (for example, Albrecht, 1997, Andreasen, 1994). Importantly, Andreasen (1994) argued the end goal of social marketing must be behavioural change and this view is widely supported by social marketing practitioners today (for example, Andreasen, 1994, Albrecht, 1997, Smith, 1998, French and Blair-Stevens, 2006, Donovan and Henley, 2010, Lee and Kotler, 2011, Almestahiri et al., 2017, Gordon et al., 2016). The first consensus definition of social marketing was reached in 2014 (AASM, 2016) and it reflects the dominant research and practical focus in the field, namely behaviour. 
Michie et al. (2008) state that interventions are more effective when they are aimed at causal determinants of both behaviour and behaviour change. Michie et al. (2008)'s work acknowledges existence of two key concepts, each of which may differ conceptually and importantly methodologically. The authors claim that behaviour change is more likely to be achieved when interventions focus on the determinants of both behaviour and behaviour change, highlighting the importance of investigating what influences change, in addition to understanding current rates of behaviour and its underlying determinants (Michie et al., 2008). In line with the call to extend research enquiry to understanding more complex relational and dynamic factors (Kriznik et al., 2018), the current study, which draws from a social marketing study theoretically grounded in Theory of Planned Behaviour (reference withheld to ensure anonymity during review), aims to conceptually and methodologically distinguish behaviour from behavioural change. The aims of this paper are threefold. First, this paper provides conceptual definitions to distinguish behaviour and behavioural change. Second this paper delivers an empirical test to demonstrate the difference between the concepts of behaviour and behaviour change. Finally, this paper offers a methodological contribution providing an illustration of the use of change scores as a method for assessing change and its determinants. This paper offers a foundational step to support the research community to step beyond behaviour towards focussing theoretical and methodological development on behavioural change, which is needed to understand how change is achieved.

\section{Social marketing's core: Behaviour or behavioural change?}

Over time social marketing benchmark criteria (SMBC) or principles emerged (Andreasen, 1994) serving as features to distinguish social marketing from other behavioural change focussed disciplines such as public policy, education and public health. The SMBC principles have served as guides for social marketing practitioners and researchers. SMBC were first introduced by Andreasen (1994), who first proposed six social marketing principles, namely; behaviour is the core criterion on which interventions are based; audience research is used to understand target audience, pre-test and monitor interventions; segmentation of the target audience to ensure utmost effectiveness and efficiency; attractive and motivational exchange as a central element of strategies; use of the full 4 P's marketing mix, and not only the promotion component; and consideration of the competition faced by the desired behaviour. SMBC have been used to determine the extent that social marketing principles have been applied within 
interventions (Carins and Rundle-Thiele, 2014, French et al., 2012, McDermott et al., 2005, Stead et al., 2007, Truss et al., 2010). More recently, research has emerged indicating that when more of the social marketing benchmark criteria are applied behavioural change is more likely (Carins and Rundle-Thiele, 2014, Xia et al., 2016). Hence, social marketers advocate the application of as many SMBC as practical in order to achieve behavioural change.

As part of the broadly adopted SMBC, behaviour is considered to be the bottom line principle for social marketing programs (Andreasen, 1994). While the aim to influence behaviour was acknowledged in the creation of the SMBC, behaviour change is considered to be the ultimate outcome of successful social marketing social marketing programs. The lack of conceptual and operational definitions providing clear distinction between the two concepts, namely behaviour and behavioural changes may explain the failure in delineating between two vastly unique concepts. Examples of social marketing programs focussing on behaviour dominate the literature (for example, Holdershaw et al., 2011, Mainsbridge et al., 2016). There are also many studies that, despite having a behaviour change focus, cross-sectional data or static data is used to empirically examine outcomes (see example in Umeh and Sharps, 2012) restricting focus to behaviour and not behavioural change. The two concepts, namely behaviour and behaviour change are conceptually and operationally distinct concepts. The two concepts will now be outlined in turn.

\section{Behaviour}

Behaviour can be conceptualised as a unit of action at one point in time. Behaviours of interest to social marketers may include lighting a cigarette, eating a hamburger or mode of travel to school over the past week. Despite agreement that behavioural change should be at the heart of social marketing programs, and an understanding that behavioural change is the defining outcome for successful programs, a focus on behaviour is evident in the literature. Consider, Carins et al. (2017) who examined heathy eating behaviour pre and post the Go Food social marketing pilot program. Post program results identified that on average diners made 1.08 unhealthy selections, 1.02 moderately healthful selections and 2.49 healthful selections. While increases in healthful selections were observed in the Carins et al. (2017) study, in line with current dominant program assessment practices data treatment was static with independent samples t-tests used to compare pre and post groups. Dominant social marketing theoretical 
focus centres attention on behaviour (for example, Manning, 2009, Plotnikoff et al., 2010) and the dominant methodological approaches employ linear and time-invariant predictors or explanatory variables (Ployhart and Kim, 2013). Consider the Theory of Planned Behaviour (TPB) (Ajzen, 1991) - an extensively used theory in social marketing (Truong and Dang, 2017), and behaviour change interventions more broadly (see Hardeman et al., 2002's review for example). The TPB states that together attitudes, subjective norms and perceived behavioural control are related to intentions which, in turn, explain behaviour (Ajzen, 1991). A review of the literature indicates that many studies applying the TPB stop at intentions, using intentions as a proxy for behaviour (for example, Forward, 2009, Arvola et al., 2008). Moreover, models extending research focus beyond intentions, predict or explain behaviour, and not behaviour change (Skår et al., 2008). TPB authors acknowledge that although TPB can be helpful as an intervention framework, it is not a theory of behaviour change (Ajzen, 2015). The TPB was developed to explain and predict intentions and behaviour at a single point in time (Ajzen, 2015). Given the dominant theoretical focus directs attention at understanding behaviour we contend research effort is needed directing conceptual and methodological focus towards understanding behavioural change and its determinants. To examine change, theoretical and methodological approaches need to examine what happens for each individual between two time points. Hence, theories of behaviour change should be at the focal point of research effort for social marketing research and this is now discussed.

\section{Refocussing to behavioural change}

In contrast to behaviour which is considered as an action at one point in time, behavioural change requires consideration of units of action (behaviours) across multiple points in time. For example, social marketers may be concerned with understanding if smokers reports smoking less cigarettes or ceasing smoking (desired behaviour change). In a recent study, David et al. (2019) utilised a dynamic methodology identifying that a total of $43.8 \%$ of people exposed to a food waste pilot program transitioned away (changed) from wasting food to not wasting food. The David et al. (2019) study employed dynamic methodologies permitting examination of the way individuals evolve over time to be undertaken. According to Michie et al. (2008) to achieve more effective interventions researchers should direct research attention towards understanding the causal determinants of both behaviour and behaviour change. As noted previously, confusion between the two terms can be seen in social marketing. Moving 
forward it is crucial that researchers differentiate between theories that focus on explaining behaviour and theories that explain behaviour change. Critically, researchers must understand that behaviour and behaviour change are conceptually and operationally different.

For one to understand the difference between the concepts, it is necessary to discern between static and dynamic. Static is referred to as a unit of observation at one point in time (behaviour), while dynamic is attributed to units of observation measured repeatedly over time (behaviour change) (Ployhart and Vandenberg, 2010). More specifically, behaviour change is characterised as the modification of the target behaviour over time (Sarafino, 1996, Sundel and Sundel, 2004). The main distinction between static and dynamic behaviour is the temporal component (Ployhart and Vandenberg, 2010). Most of the research in social sciences utilises a cross-sectional design, looking at static behaviour, which does not provide enough insight into how behaviour change over time can be achieved (Pitariu and Ployhart, 2010). Using timeinvariant approaches involves examinations of explanatory and/or causal relationships between predictors, usually suggesting that $\mathrm{X}$ is associated with $\mathrm{Y}$, for example. In these models, time is neglected, with determinant changes as well as changes in behaviour ignored.

The need for longitudinal studies to investigate change is emphasised by Singer and Willett (2003, p.3) who state that "cross-sectional data - so easy to collect and so widely available will not suffice". In addition, even when a longitudinal design is applied, it is common to see researchers assess change by using independent variables captured at the first point in time regressed on a dependent variable (e.g. behaviour) measured in the second point in time. For example, Schuster et al. (2016) employed mixed ANOVA to assess whether injunctive and descriptive norms for respondents participating in a social marketing program changed significantly over time when compared to respondents that did not participate in the program. As explained by Kher and Serva (2014), this cannot be considered a longitudinal design, since this method uses variables observed only once, and not longitudinal changes within the same individual using the same variable measured repeatedly across time.

Dynamic theories operationalise constructs examining within variable changes for $\mathrm{X}$ and $\mathrm{Y}$ over time (Mitchell and James, 2001) to then assess interrelationships between the constructs. In these cases, relationships between variables are much more complex, since change can occur in different directions (e.g. incremental, discontinuous, positively and negatively). Further, this 
paper acknowledges that not all individuals change. The concept of change and how (or even if) it can be assessed has been widely discussed over time (see Cronbach and Furby, 1970, Rogosa et al., 1982, Ployhart and Vandenberg, 2010, Kher and Serva, 2014, Chan, 1998, Bereiter, 1962). A simple form of assessing change involves the calculation of a change (or difference) score. A change score is an estimate of true change, calculated by the difference (T2 - T1) between time point 1 (T1) and time point 2 (T2). The use of a change score has been discussed and some researchers criticise its use citing reliability and validity issues (see Cronbach and Furby, 1970, Linn and Slinde, 1977). However, other researchers have found such claims to be unfounded (Rogosa et al., 1982, Allison, 1990, Chan, 1998, Finch and Shim, 2018, Fu and Holmer, 2016), delivering evidence suggesting that a change score is a simple and unbiased measure of change. Dalecki and Willits (1991) compared three change methods employing regression analyses, finding that difference scores as a dependent variable is preferable.

Taken together, a lack of distinction between the concepts of behaviour and behavioural change is clearly evident from the social marketing and wider behavioural change literature. In addition, it is also clear that behaviour, rather than behavioural change has dominated social marketing research and practice to date. Due to the conceptual and operational distinctions between behaviour and behaviour change, one cannot assume that explaining static behaviour is the same as explaining dynamic behaviour or behaviour change (Ployhart and Vandenberg, 2010). Hence, determinants of behaviour at a single point in time may not be the same as determinants of behaviour change. The aims of this study are threefold. First, this paper has conceptually distinguished between behaviour and behavioural change. Second this paper delivers an empirical test to demonstrate the difference between the concepts of behaviour and behaviour change. Finally, this paper offers a methodological contribution providing an illustration of the use of change scores as a method for assessing change and its determinants. This paper offers a foundational step to support the research community to step beyond behaviour towards focussing theoretical and methodological development on behavioural change, which is needed to understand how to achieve changes sought. 


\section{Empirical illustration}

\section{Method}

Statistical analyses were conducted to empirically examine factors explaining static behaviour and dynamic behavioural change drawing on data from a longitudinal study conducted by Social Marketing@ Griffith in the context of increasing physical activity for children.

\section{Design}

Walk to School is a state wide program conducted annually in Victoria, Australia. The program's objective is to increase the number of times children walk to and from school each week. The maximum number of times a child can walk to and from school is 10 times within a one week period. The intervention occurred across a one month duration and participation in the program was completely voluntary. Parents and carers were asked to answer an online survey at baseline (T1) prior to program commencement, and a follow-up survey (T2) was completed one month following the program to examine program effects. At baseline the survey was distributed via email to a mailing list of people who had agreed to be contacted for research purposes, and was also promoted through social media platforms such as Facebook and Twitter. Mailing lists were provided by the partnering organisation, VicHealth.

\section{Participants}

The online survey was completed by 2,001 people at baseline (T1), and a total of 375 carers whose children had participated in Walk to School participated in program evaluation at T2. Therefore, examination of both static and dynamic data was restricted to $n=375$. The questionnaire was answered by parents or carers of the children, and gender and age were reported for both the children and parents or carers at baseline. Child's gender was reportedly $50 \%$ female and 50\% male. Parent or carer's gender was $85 \%$ female and $15 \%$ male. The mode age for children in the study was 6 years old. The majority of parents or carers were between 40 to 44 years old. Income and education level were also reported. Most of the parents and carers stated receiving a yearly wage of $\$ 104,000$ and over, and having a University degree indicating the sample were highly educated and their wages were above the national average. 


\section{The Static Measures}

The social marketing program evaluation was theoretically guided and measures of reliability and validity were evaluated and both were assured (Schuster et al., 2016). The survey contained demographic, psychographic and behavioural questions. Psychographic measures utilised in this study included intentions, affective and instrumental attitudes, descriptive and injunctive norms, perceived behavioural control and barriers. An illustration of the static measures and their origins in the literature are shown in Table 1 below.

Table 1. Psychographic Measures

\begin{tabular}{|c|c|c|}
\hline Variables & Example measure & Source \\
\hline Intention & $\begin{array}{l}\text { I intend to increase the number of times } \\
\text { the child walks to/from school during the } \\
\text { next week. [Extremely unlikely } \\
\text { Extremely likely] }\end{array}$ & $\begin{array}{l}\text { Rundle-Thiele et al. } \\
\text { (2013) }\end{array}$ \\
\hline Affective attitudes & $\begin{array}{l}\text { Walking to/from school is: [Unpleasant } \\
\text { Pleasant] }\end{array}$ & Scott et al. (2007) \\
\hline $\begin{array}{l}\text { Instrumental } \\
\text { attitudes }\end{array}$ & $\begin{array}{l}\text { Walking to/from school is: [Harmful | } \\
\text { Beneficial] }\end{array}$ & Scott et al. (2007) \\
\hline Descriptive norms & $\begin{array}{l}\text { Many of my friends' children walk to/from } \\
\text { school. [Strongly disagree | Strongly } \\
\text { agree] }\end{array}$ & $\begin{array}{l}\text { Perugini and Conner } \\
(2000)\end{array}$ \\
\hline Injunctive norms & $\begin{array}{l}\text { People who are important to me think the } \\
\text { child should/should not walk to/from } \\
\text { school. [Should not } \mid \text { Should] }\end{array}$ & $\begin{array}{l}\text { Rhodes and Courneya } \\
(2003)\end{array}$ \\
\hline $\begin{array}{l}\text { Perceived } \\
\text { behavioural control }\end{array}$ & $\begin{array}{l}\text { Whether or not the child walks to/from } \\
\text { school in the next week is entirely up to } \\
\text { me. [Strongly disagree / Strongly agree] }\end{array}$ & $\begin{array}{l}\text { Rhodes and Courneya } \\
(2003)\end{array}$ \\
\hline Barriers & $\begin{array}{l}\text { Streets are dangerous to cross along the } \\
\text { route to/from school. [Strongly disagree } \\
\text { Strongly agree] }\end{array}$ & Napier et al. (2011) \\
\hline
\end{tabular}


For the static behavioural measure, participants were asked to indicate how many times their children walked to (zero to five mornings per week) and from (zero to five afternoons per week) school during the previous week. The two measures were combined into one scale, in which 0 was the lowest and 10 was the highest value.

\section{Statistical Analyses}

Prior to undertaking statistical analyses, data was cleaned, coded and participants that responded to surveys in both $\mathrm{T} 1$ and $\mathrm{T} 2$ were matched $(\mathrm{n}=325)$, using SPSS v.25. Next, reliability analyses were conducted using Cronbach's alpha to ensure validity of measures (all measures had a Cronbach's alpha $>0.7)$. Next, individual psychographic items were computed into scales. For statistical analysis of static behaviour, all carers reporting no behaviour change $(n=164)$ were removed from the data set to ensure the same individuals were being compared both statically and dynamically $(n=161)$. The final step was undertaking a multiple linear regression.

\section{Creating dynamic measures}

In order to test dynamic behaviour change, change scores (Allison, 1990) were created for behaviour and all psychographic measures. Given that behavioural change is the conceptual focus for the present study, respondents reporting no change in their child's walking to and from school behaviour were removed from analysis to focus on understanding change. This resulted in 164 cases being removed from the dataset limiting analysis to people that reported changes in walking behaviour; both desired and undesired change $(n=161)$ (see Figure 1). Once change variables (T2-T1) were created for behaviour and all psychographic variables, multiple linear regressions were performed following the same procedure applied on static measures.

\section{Results}

Descriptive analyses of behaviour and behaviour change were performed prior to multiple linear regression to visualise operational differences between the two constructs (see Figure 1 and Figure 2). 
Figure 1. Illustration of Behaviour (number of times the child walked to and from school)

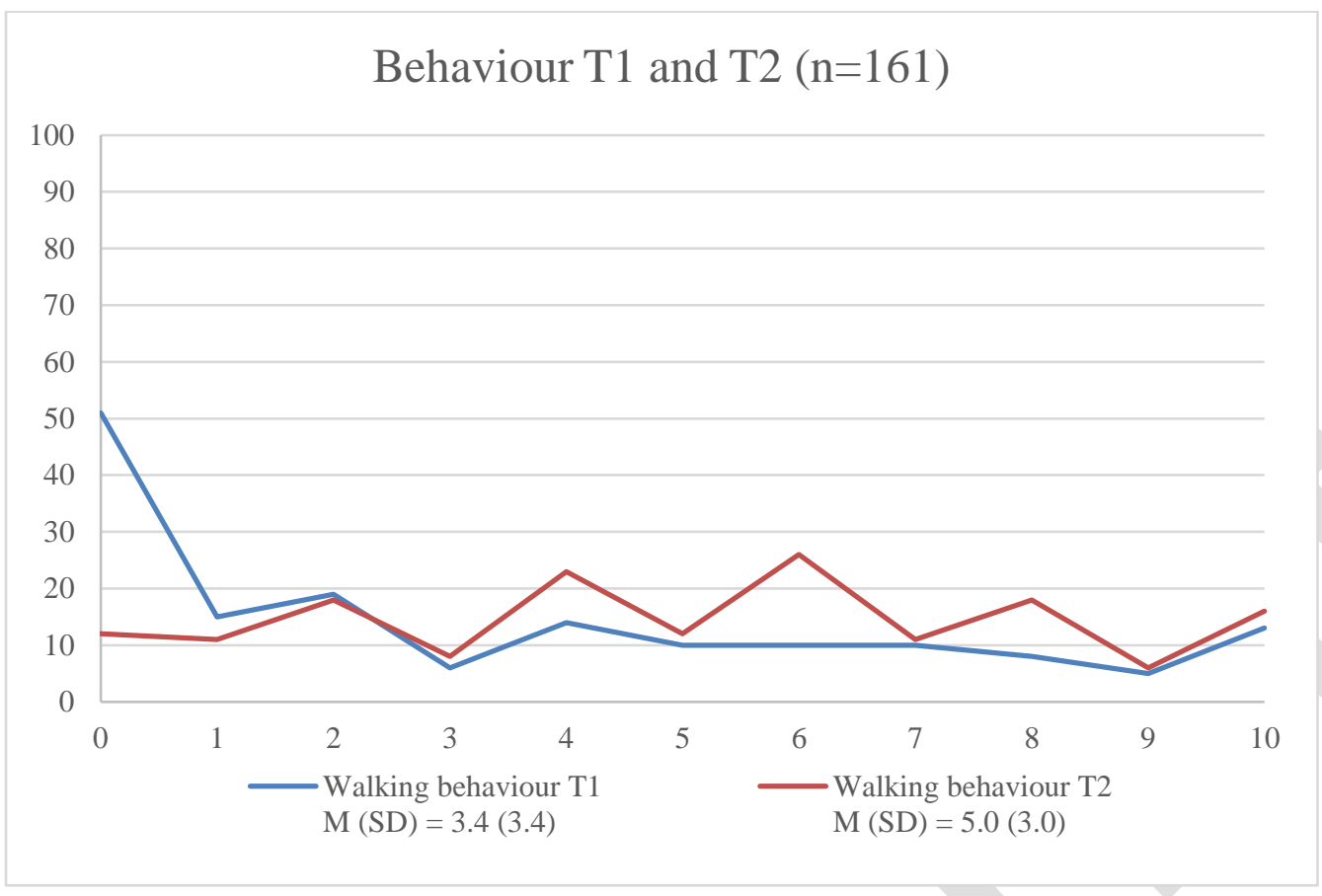

Figure 2. Illustration of Behaviour Change (change in number of times the child walked to and from school)

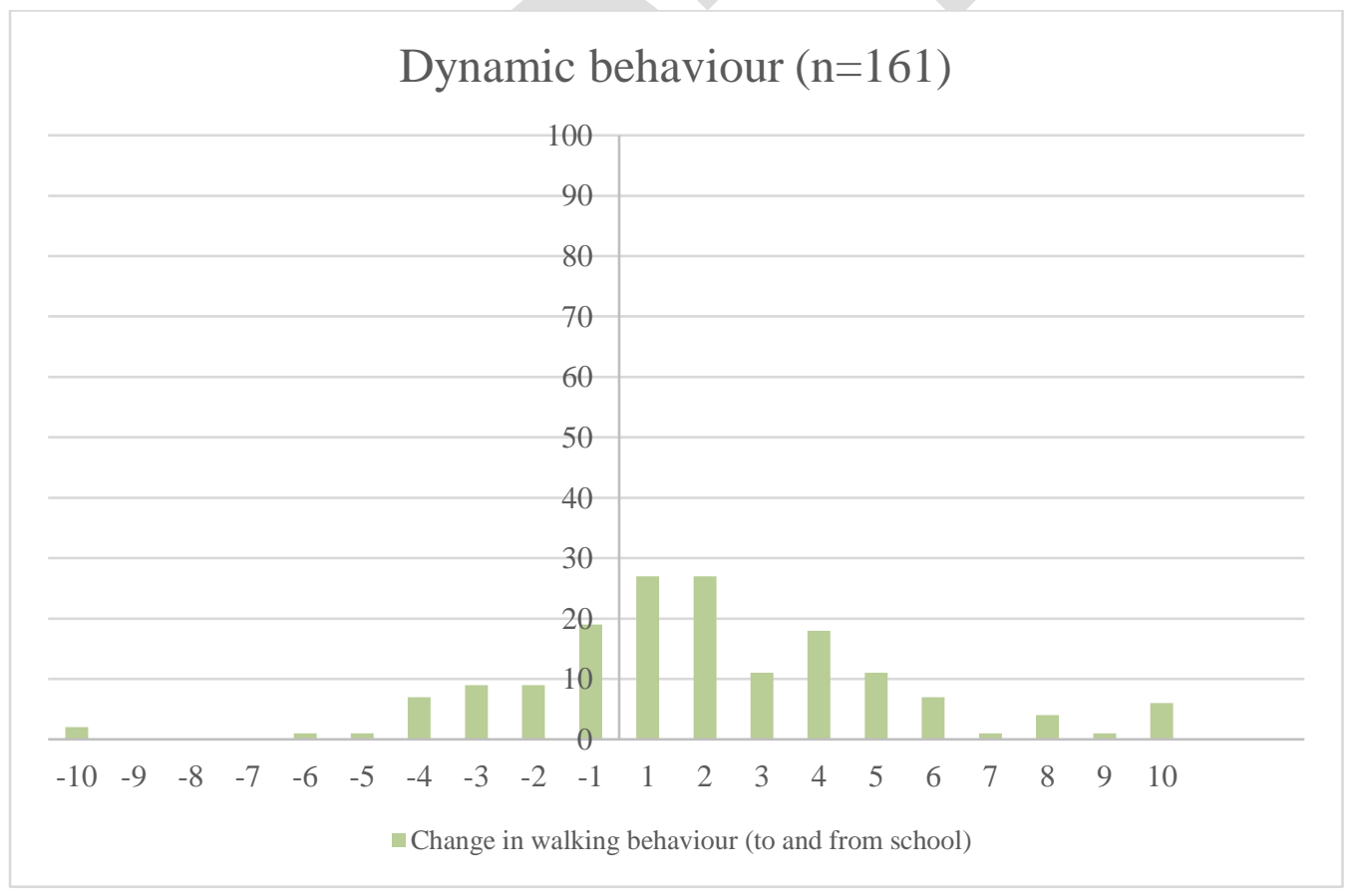


As seen in the illustrations above, behaviour and behavioural change are operationally distinct. Figure 1 illustrates that walking to and from school in the past week directs attention to the number of times a child has walked to and from school over the past week (one period of time) with data ranging between 0 times and as many as 10 times per week. Figure 2 involves use of change data that has subtracted the number of times a carer reports that their child walked to school after the intervention from the number of times their child walked to school in a week prior to the intervention. Changes reported by carers can be positive or negative indicating change in the desired and undesired directions, respectively. Means and standard deviations for psychographic measures in the study are reported in Table 2 for static and dynamic data treatments.

Table 2. Psychographic Descriptive Statistics

\begin{tabular}{|l|l|l|}
\hline & Static Mean (SD) & Dynamic Mean (SD) \\
\hline Intention & $3.4(2.0)$ & $0.3(1.7)$ \\
\hline Affective attitudes & $5.6(1.5)$ & $0.0(1.6)$ \\
\hline Instrumental attitudes & $5.9(1.7)$ & $0.0(1.6)$ \\
\hline Descriptive norms & $4.4(1.6)$ & $0.1(1.2)$ \\
\hline Injunctive norms & $4.8(1.7)$ & $0.2(1.5)$ \\
\hline Perceived behavioural control & $5.4(1.7)$ & $0.0(1.5)$ \\
\hline Barriers & $3.8(1.7)$ & $-0.1(1.2)$ \\
\hline
\end{tabular}

Behaviour change is extremely complex, and there are multiple factors that need to be considered, such as the direction of change (Kher and Serva, 2014) and the magnitude of change. Examination of static data indicates that on average attitudes (affective and instrumental) are high, social norms were neutral and intentions to increase walking to and from school were low for carers reporting changes in walking to and from school. Examination 
of dynamic psychographic data indicates that few changes in Theory of Planned Behaviour constructs such as attitudes and perceived behaviour control occurred. This is to be expected given the Theory of Planned Behaviour was not used to guide intervention design or implementation. Earlier research had indicated that social norms changed as a result of program participation (Schuster et al., 2016). Further examination of dynamic data indicates that on average perceived barriers of walking to and from school were lowered, while injunctive norms and carers intentions to walk to and from school increased as a result of participation in the social marketing program. Prior to data analysis, correlations analyses were performed to understand the association between all variables for both static and dynamic data (see results in Tables 3 and 4).

Table 3. Correlations matrix - Static Behaviour

\begin{tabular}{|c|c|c|c|c|c|c|c|c|}
\hline Variables & $\begin{array}{l}\text { Walk to } \\
\text { and from } \\
\text { school }\end{array}$ & Intention & $\begin{array}{l}\text { Affective } \\
\text { Attitudes }\end{array}$ & $\begin{array}{l}\text { Instrumental } \\
\text { attitudes }\end{array}$ & $\begin{array}{l}\text { Descriptive } \\
\text { norms }\end{array}$ & $\begin{array}{l}\text { Injunctive } \\
\text { norms }\end{array}$ & PBC & Barriers \\
\hline $\begin{array}{l}\text { Walk to and } \\
\text { from school }\end{array}$ & - & & & & & & & \\
\hline Intention & $.254 * * *$ & - & & & & & & \\
\hline $\begin{array}{l}\text { Affective } \\
\text { Attitudes }\end{array}$ & $.196 * * *$ & .057 & & & & & & \\
\hline $\begin{array}{l}\text { Instrumental } \\
\text { attitudes }\end{array}$ & $.231 * * *$ & .011 & $.830 * * *$ & - & & & & \\
\hline $\begin{array}{l}\text { Descriptive } \\
\text { norms }\end{array}$ & $.347 * * *$ & $.299 * * *$ & 0.070 & .073 & - & & & \\
\hline $\begin{array}{l}\text { Injunctive } \\
\text { norms }\end{array}$ & $.471 * * *$ & $.393 * * *$ & $.229 * * *$ & $.232 * * *$ & $.447 * * *$ & - & & \\
\hline PBC & $.252 * * *$ & $.206 * * *$ & .005 & -.010 & $.134 *$ & $.263 * * *$ & - & \\
\hline Barriers & $-.524 * * *$ & $-.270 * * *$ & -.077 & $-.148 * *$ & $-.279 * * *$ & $-.466 * * *$ & $-193 * * *$ & - \\
\hline
\end{tabular}

All tests are two tailed. $*=\mathrm{p}<0.05 ; * *=\mathrm{p}<0.01 ; * * *=\mathrm{p}<0.001$ (Note: Sample size differed in the variables). 
Table 4. Correlations matrix - Dynamic Behaviour

\begin{tabular}{|c|c|c|c|c|c|c|c|c|}
\hline Variables & $\begin{array}{l}\text { Walk to } \\
\text { and from } \\
\text { school } \\
\text { change }\end{array}$ & $\begin{array}{l}\text { Intention } \\
\text { change }\end{array}$ & $\begin{array}{l}\text { Affective } \\
\text { Attitudes } \\
\text { change }\end{array}$ & $\begin{array}{l}\text { Instrumental } \\
\text { attitudes } \\
\text { change }\end{array}$ & $\begin{array}{l}\text { Descriptive } \\
\text { norms } \\
\text { change }\end{array}$ & $\begin{array}{l}\text { Injunctive } \\
\text { norms } \\
\text { change }\end{array}$ & $\begin{array}{l}\text { PBC } \\
\text { change }\end{array}$ & $\begin{array}{l}\text { Barriers } \\
\text { change }\end{array}$ \\
\hline $\begin{array}{l}\text { Walk to and } \\
\text { from school } \\
\text { change }\end{array}$ & - & & & & & & & \\
\hline $\begin{array}{l}\text { Intention } \\
\text { change }\end{array}$ & -.121 & - & & & & & & \\
\hline $\begin{array}{l}\text { Affective } \\
\text { Attitudes } \\
\text { change }\end{array}$ & -.121 & .021 & - & & & & & \\
\hline $\begin{array}{l}\text { Instrumental } \\
\text { attitudes } \\
\text { change } \\
\end{array}$ & -.050 & .053 & $.768 * * *$ & - & & & & \\
\hline $\begin{array}{l}\text { Descriptive } \\
\text { norms } \\
\text { change }\end{array}$ & .136 & $.201 * * *$ & $.136 *$ & $.151 * *$ & & & & \\
\hline $\begin{array}{l}\text { Injunctive } \\
\text { norms } \\
\text { change }\end{array}$ & $.277 * *$ & .077 & $.129 *$ & $.138 *$ & $.301 * * *$ & - & & \\
\hline PBC change & .084 & .083 & .035 & .067 & .045 & .000 & - & \\
\hline $\begin{array}{l}\text { Barriers } \\
\text { change }\end{array}$ & -.110 & -.038 & .071 & .044 & $-.158 * *$ & $-.118 *$ & -.009 & - \\
\hline
\end{tabular}

All tests are two tailed. $*=p<0.05 ; * *=p<0.01 ; * * *=p<0.001$ (Note: Sample size differed in the variables).

\section{Determinants of Behaviour}

A multiple linear regression of static behaviour assessed the extent that intention, affective attitude, instrumental attitude, descriptive norm, injunctive norm, PBC and barriers (all measured at T2) could explain walking to and from school in T2 (see Table 5).

Table 5. Static Behaviour $(n=146)$

\begin{tabular}{lcccl}
\hline $\begin{array}{l}\text { Walking to and from } \\
\text { behaviour }\end{array}$ & school & $\boldsymbol{\beta}$ & $\mathbf{s r}^{\mathbf{2}}$ & $\mathbf{P}$ \\
\hline Intention T2** & $\mathbf{- 0 . 2 1 4}$ & $\mathbf{0 . 0 4 1}$ & $\mathbf{0 . 0 1 0}$ \\
Affective attitudes T2 & -0.206 & 0.008 & 0.263 \\
Instrumental attitudes T2 & 0.305 & 0.017 & 0.094 \\
Descriptive norms T2 & 0.030 & 0.001 & 0.719
\end{tabular}




$\begin{array}{lccc}\text { Injunctive norms T2 } & 0.161 & 0.020 & 0.069 \\ \text { Perceived behavioural control T2 } & 0.139 & 0.013 & 0.139 \\ \text { Barriers T2* } & \mathbf{- 0 . 1 6 5} & \mathbf{0 . 0 2 4} & \mathbf{0 . 0 4 5}\end{array}$

The model showed statistical significance (Adj. $\left.\mathrm{R}^{2}=.131, F(7,138)=31.598, \mathrm{p}<.001\right)$. Barriers to walking to and from school explained static behaviour at T2 $(\mathrm{B}=-.165, \mathrm{p}=0.045)$. Intention $(\mathrm{B}=-0.214, \mathrm{p}<.01)$ was also a statistically significant factor explaining walking to and from school at T2.

\section{Determinants of Behavioural Change}

Following the same multiple linear regression approach employed for static variables a second multiple linear regression was performed using dynamic data (change scores) to understand whether intention change, affective attitude change, instrumental attitude change, descriptive norm change, injunctive norm change, PBC change and barrier change could explain behavioural change. Behavioural change was operationalised as the carers reported change in their child's walking to and from school (see descriptive statistics in Table 2 and results of dynamic data analysis in Table 6).

Table 6. Behavioural Change $(n=132)$

\begin{tabular}{llll}
\hline $\begin{array}{l}\text { Walking to and from school } \\
\text { behaviour change }\end{array}$ & $\boldsymbol{\beta}$ & $\mathbf{s r}^{\mathbf{2}}$ & $\mathbf{P}$ \\
\hline Intention change & -0.105 & 0.010 & 0.221 \\
Affective attitudes change & -0.181 & 0.013 & 0.170 \\
Instrumental attitudes change & 0.019 & 0.000 & 0.888 \\
Descriptive norms change & 0.094 & 0.007 & 0.314 \\
Injunctive norms change** & $\mathbf{0 . 2 5 9}$ & $\mathbf{0 . 0 5 8}$ & $\mathbf{0 . 0 0 5}$ \\
Perceived behavioural control change & 0.053 & 0.003 & 0.529 \\
Barriers change & -0.077 & 0.005 & 0.378 \\
\hline
\end{tabular}

A dynamic modelling method also yielded a statistically significant model (Adj. $\mathrm{R}^{2}=.097$, $F(7,124)=3.000, \mathrm{p}<.01)$. With a weaker variance explained in this model, the only variable found to be statistically significant in explaining changes in walking to and from school was a 
change in injunctive norms $(\mathrm{B}=.259, \mathrm{p}<.01)$. A dynamic modelling approach indicates a focus on achieving a change in behaviour would require efforts to be focussed on increasing injunctive norms.

\section{Discussion}

According to Michie et al. (2008) interventions are more effective when they are aimed at causal determinants of both behaviour and behaviour change; which indicates an understanding that these concepts are theoretically and methodologically different. In line with the call to extend research enquiry to understanding more complex relational and dynamic factors (Kriznik et al., 2018) the current study aimed to 1) conceptually distinguish between behaviour and behavioural change, 2) deliver an empirical test to demonstrate the difference between the concepts of behaviour and behaviour change and 3) offer a methodological illustration of the use of change scores to assess behavioural change and its determinants.

Systematic literature reviews across different disciplines (e.g. social marketing, public health, psychology) that focus on behaviour change have demonstrated a lack of theory use in behavioural change programs (see Luca and Suggs, 2013, Prestwich et al., 2014, Truong and Hall, 2013, Keogh et al., 2015, Truong and Dang, 2017). These reviews show that the most commonly applied theories in behaviour change interventions (for example, the Theory of Planned Behaviour) are behavioural theories, with dominant data treatments drawing on static measures. A behaviour focus dominates social marketing research enquiry, which is surprising given the conceptual and operational differences between behaviour and behavioural change. While other social sciences (e.g. organisational science) acknowledge dynamic and static treatment of data (see Pitariu and Ployhart, 2010, Ployhart and Vandenberg, 2010), limited consideration had been directed towards understanding the determinants of behavioural change in social marketing to date.

In an article calling for better theory for behaviour change across different disciplines such as organisational sciences, sociology and psychology, Mitchell and James (2001) emphasise the importance of considering time and behaviour as dynamic, when building models and theories. The authors state that "[...] most of our research involves causal hypotheses and designs presumed to support causal inferences. Yet, very few papers specifically address, from a 
theoretical perspective, the time elements involved in X causing Y" (Mitchell and James, 2001). Several years later, behavioural researchers continue to call for theories of change, and for research methodologies that go beyond cross-sectional design, and look at change as a dynamic process (e.g. Ployhart and Vandenberg, 2010, Pitariu and Ployhart, 2010, Jebb et al., 2015, Wang et al., 2017, Stritch, 2017). Since change is a complex process, and confusion between the concepts of behaviour and behaviour change is evident in the literature, this paper has taken an important step, demonstrating that conceptual and operational definitions for behaviour and behavioural change are different. Moreover, the results of this study point to the need for research attention to expand to understanding of behavioural change. Theory serves as a roadmap to direct effort and a theories of behaviour change need to be developed by the research community to deliver a framework that practitioners can use.

Drawing on empirical data and utilising the same constructs, this study examined both static and dynamic data to empirically examine whether the determinants of behavioural change were the same as behaviour. Differences in explanatory variables and the extent of variance explained were observed between static and dynamic data treatments delivering empirical evidence that behaviour and behavioural change are conceptually and operationally distinct. When comparing results from the static and dynamic models, the static model showed that only intentions and barriers explained behaviour at Time point 2. However, statistical analysis utilising dynamic data treatment found that a change in injunctive norms (important others' approval of the child walking to school) explained a change in walking to and from school behaviour. Importantly, results show a positive relationship, suggesting that an increase in injunctive norms leads to an increase in walking to and from school behaviour.

\section{Behaviour vs behavioural change}

Interpretation of the data from the separate analyses conducted for this study indicates that although rates of walking to and from school could be explained by barriers (for example, distance to school), and whether the parents intended to walk to school or not, to change this behaviour, one cannot assume that changing intentions or perceived barriers would lead to a change in walking to school behaviour. This study provided initial evidence that behaviour and the factors explaining behaviour may not be the same as the factors that explain behavioural change. Moving forward researchers must expand their focus to understanding how and why 
people change their behaviour. In this study, a program that aimed to encourage more children to walk to school delivered changes in social norms, which in turn explained increases in walking to school behaviour. These results provide important theoretical implications, since most widely used theories in social marketing are behavioural, and not behavioural change focussed theories. While behavioural theories are important, we cannot assume they are capturing factors that bring about actual change. Taken together, the results of the current study suggest research attention needs to be directed towards dynamic methodologies to re-centre research attention on behavioural change and not behaviour, which dominates current practice.

\section{Change scores to assess behaviour change}

The final contribution of this paper is methodological. Specifically this paper illustrates one possible method that may be used to assess behavioural change. Change scores were captured for both dependent and independent variables (for examples of change score use see Allison, 1990, van Breukelen, 2013, Castro-Schilo and Grimm, 2018) ensuring all data collected longitudinally (pre and post intervention) was treated dynamically and not statically as commonly occurs in social marketing practice (for examples of static data treatment see Holdershaw et al., 2011, Mainsbridge et al., 2016). Utilisation of the change score method identified unique associations explaining behavioural change that were not evident in static data treatment. The addition of dynamic data analysis utilising change scores as recommended by Michie et al. 2008 extended insights for social marketing practitioners. Specifically, static data analysis indicated that distance lived from school and perceived barriers explained the extent of current walking to school behaviour. The addition of dynamic analysis identified that changes in norms explained behavioural change. Social marketing programs that increased social norms increased walking to school. The limitations of change score methodologies are known (see Cronbach and Furby, 1970, Linn and Slinde, 1977), and we acknowledge that utilisation of a change score methodology may not be the optimal method for treating change data, which offers a rich area for future research. This study makes an important methodological contribution to the field of social marketing, providing an illustration of how data can be treated dynamically, expanding the focus from assessing determinants of behaviour to understanding the determinants of behavioural change. 


\section{Managerial Implications}

This study demonstrated the importance of distinguishing between behaviour and behaviour change, identifying that determinants of one may not be the same as the other. Application of theories focussing attention on behaviour and not behavioural change in program design may lead social marketing practitioners to misallocate resources if the end goal is behavioural change. By expanding the theoretical lens and methodological practice from behaviour to also behaviour change, insight into behavioural change determinants can be gained, which can then be used to inform strategic decision making to guide behaviour change program investment and implementation.

In the context of Walk to School, for example, it would be recommended that strategies to increase injunctive norms should be put in place. Injunctive norms, as previously defined, are perceptions of how important others think it is for you to engage in the behaviour. In the walking to school context, a strategy to increase injunctive norms could be to have walking to school groups. Strategies communicating approval of important others (e.g. teachers, Principals, grandparents and other parents) of children who walk to and from school would also assist to increase injunctive norms. Examples of tools to implement such strategies could be posters throughout the school, teachers leading walking groups to schools, Principles greeting children (and parents) who walk to school at the school gates, teachers promoting the importance of walking groups in parents' meetings, and more.

It is crucial that behaviour change programs have a longitudinal research design. Longitudinal assessments are essential to advance knowledge of behaviour change ensuring optimisation of resources. Evaluative methods need to go beyond prediction of behaviour to identification of behaviour change determinants. This is only possible when researchers treat data dynamically.

\section{Limitations and Future Research}

As with any research, there are limitations that need to be acknowledged in the present study. Although, change scores are acknowledged in the literature as one measure of change over time (Allison, 1990, Borenstein et al., 2009), some discussion regarding reliability issues and whether or not calculation of change scores is the best method for explaining change over time (Rogosa and Willett, 1983, Kessler, 1977). Some authors have suggested a stronger method for 
explaining change over time is the latent growth curve model (LGM) (Pitariu and Ployhart, 2010, Ployhart and Kim, 2013, Rogosa et al., 1982). However, minimum criteria for utilising LGC have to be met. For example, a minimum sample size of at least 200 cases in each time point is required (Boomsma and Hoogland, 2001). Moreover, when the focus of the LGM is on individual changes, data must be acquired over at least three points in time (Byrne, 2013), which may exceed budget capabilities for many behavioural change programs.

Other methods that are able to assess dynamic behaviour need to be explored. An example of a method that allows for longitudinal assessment of change in a dynamic form is the Hidden Markov Model (HMM), also referred to as Latent Transition Analysis (see David et al., 2019 for HMM application in a food waste context). It is recommended that HMM application be extended to assess its capacity to model behaviour and behavioural change determinants. Consideration of a range of dynamic evaluative methods would advance understanding of the methods that can be applied reliably and cost-effectively to examine and develop understanding of behavioural change. Such consideration would determine whether simpler evaluation methodologies are capable of delivering equivalent diagnostic information to complex modelling alternatives. The product of which would be evaluation methods that produce high quality diagnostic information by collecting only necessary data (and no more) creating the most user friendly and cost effective approach.

This study used secondary data to illustrate the utility of using change scores to assess behavioural change. However, use of existing data limits understanding of change determinants to the variables that were measured in the initial study. In this case change data was limited to psychographic and behavioural variables and self-report data. The data that formed the basis for this paper was individual level data and additional research is recommended to widen focus beyond individuals to capture changes in the environment (e.g. infrastructure changes that would support sustained behaviour change, such as walking paths and school crossings) and objective behaviour measures. For future research, it is recommended that environmental and social factors are collected and included in dynamic change assessments.

In light of limitations, it is recommended that the model tested in this study is repeated across a range of conditions before it can be fully accepted as a potential Walk to School Behaviour Change Theory. More data and testing is needed prior to drawing absolute conclusions or 
proposing effective solutions. Replication across the walking to school context is necessary. Similarly, to broaden beyond the current context, testing of studies in other behavioural contexts is needed. The final limitation of the present study is removal of carers reporting no change from the data set and the simultaneous consideration of both negative and positive change. Future research is also recommended to empirically examine the carers who report no change to determine if drivers for a lack of change can be identified and to direct research attention at understanding if the drivers of desired and undesired change vary.

\section{Conclusion}

The need to understand more complex relational and dynamic factors has previously been called for (Kriznik et al., 2018) and while Michie et al.'s (2008) work had previously highlighted the importance of investigating what influences change to extend our understanding beyond behaviour (Michie et al., 2008) examination of the evidence base identified a lack of conceptual and methodological distinction between behaviour and behavioural change. In line with these calls the current study conceptually and methodologically distinguished behaviour from behavioural change. This paper offers a foundational step to support the social marketing research community to step beyond behaviour towards focussing theoretical and methodological development on behavioural change, which is needed to understand how to achieve changes sought. 


\section{References}

AASM. 2016. What is social marketing? [Online]. Available: https://www.aasm.org.au/whatis-social-marketing/.

Ajzen, I. 1991. The theory of planned behavior. Organizational Behavior and Human Decision Processes, 50, 179-211.

Ajzen, I. 2015. The theory of planned behaviour is alive and well, and not ready to retire: a commentary on Sniehotta, Presseau, and Araújo-Soares. Health Psychology Review, 9, 131-137.

Albrecht, T. L. 1997. Defining social marketing: 25 years later. Social Marketing Quarterly, $3,21-23$.

Allison, P. D. 1990. Change scores as dependent variables in regression analysis. Sociological methodology, 20, 93-114.

Almestahiri, R. d., Rundle-Thiele, S., Parkinson, J. \& Arli, D. 2017. The Use of the Major Components of Social Marketing: A Systematic Review of Tobacco Cessation Programs. Social Marketing Quarterly, 1524500417704813.

Andreasen, A. R. 1994. Social marketing: Its definition and domain. Journal of public policy \& marketing, 108-114.

Arvola, A., Vassallo, M., Dean, M., Lampila, P., Saba, A., Lähteenmäki, L. \& Shepherd, R. 2008. Predicting intentions to purchase organic food: The role of affective and moral attitudes in the Theory of Planned Behaviour. Appetite, 50, 443-454.

Bereiter, C. 1962. Using tests to measure change. Journal of Counseling \& Development, 41, 6-11.

Boomsma, A. \& Hoogland, J. J. 2001. The robustness of LISREL modeling revisited. Structural equation models: Present and future. A Festschrift in honor of Karl Jöreskog, 139-168.

Borenstein, M., Hedges, L. V., Higgins, J. \& Rothstein, H. R. 2009. Effect sizes based on means. Introduction to Meta-Analysis, 21-32.

Bull, F. C. \& Bauman, A. E. 2011. Physical inactivity: the "Cinderella" risk factor for noncommunicable disease prevention. Journal of health communication, 16, 13-26.

Byrne, B. M. 2013. Structural equation modeling with AMOS: Basic concepts, applications, and programming, Routledge.

Carins, J. \& Rundle-Thiele, S. 2014. Eating for the better: a social marketing review (20002012). Public Health Nutrition, 17, 1628-1639.

Castro-Schilo, L. \& Grimm, K. J. 2018. Using residualized change versus difference scores for longitudinal research. Journal of Social and Personal Relationships, 35, 32-58. 
Chan, D. 1998. The conceptualization and analysis of change over time: An integrative approach incorporating longitudinal mean and covariance structures analysis (LMACS) and multiple indicator latent growth modeling (MLGM). Organizational Research Methods, 1, 421-483.

Cronbach, L. J. \& Furby, L. 1970. How we should measure" change": Or should we? Psychological bulletin, 74, 68.

Dalecki, M. \& Willits, F. K. 1991. Examining change using regression analysis: Three approaches compared. Sociological Spectrum, 11, 127-145.

Donovan, R. \& Henley, N. 2010. Principles and practice of social marketing: an international perspective, Cambridge University Press.

Finch, W. H. \& Shim, S. S. 2018. A Comparison of Methods for Estimating Relationships in the Change Between Two Time Points for Latent Variables. Educational and Psychological Measurement, 78, 232-252.

Forward, S. E. 2009. The theory of planned behaviour: The role of descriptive norms and past behaviour in the prediction of drivers' intentions to violate. Transportation Research Part F: traffic psychology and behaviour, 12, 198-207.

French, J. \& Blair-Stevens, C. 2006. Social marketing national benchmark criteria. UK: National Social Marketing Centre.

French, J., Farrell, T. \& Gordon, R. 2012. Critical social marketing: Investigating alcohol marketing in the developing world. Journal of Social Marketing, 2, 138-156.

Fu, R. \& Holmer, H. K. 2016. Change score or follow-up score? Choice of mean difference estimates could impact meta-analysis conclusions. Journal of clinical epidemiology.

Gordon, R., Russell-Bennett, R. \& Lefebvre, R. C. 2016. Social marketing: the state of play and brokering the way forward. Taylor \& Francis.

Hardeman, W., Johnston, M., Johnston, D., Bonetti, D., Wareham, N. \& Kinmonth, A. L. 2002. Application of the theory of planned behaviour in behaviour change interventions: A systematic review. Psychology and health, 17, 123-158.

Holdershaw, J., Gendall, P. \& Wright, M. 2011. Predicting blood donation behaviour: further application of the theory of planned behaviour. Journal of Social Marketing, 1, 120132.

Jebb, A. T., Tay, L., Wang, W. \& Huang, Q. 2015. Time series analysis for psychological research: examining and forecasting change. Frontiers in Psychology, 6, 727.

Keogh, A., Tully, M. A., Matthews, J. \& Hurley, D. A. 2015. A review of behaviour change theories and techniques used in group based self-management programmes for chronic low back pain and arthritis. Manual therapy, 20, 727-735.

Kessler, R. C. 1977. The use of change scores as criteria in longitudinal survey research. Quality \& Quantity, 11, 43-66. 
Kher, H. V. \& Serva, M. A. 2014. Changing the way we study change: Advocating longitudinal research in MIS. ACM SIGMIS Database, 45, 45-60.

Kriznik, N. M., Kinmonth, A. L., Ling, T. \& Kelly, M. P. 2018. Moving beyond individual choice in policies to reduce health inequalities: the integration of dynamic with individual explanations. Journal of Public Health.

Lee, N. R. \& Kotler, P. 2011. Social marketing: Influencing behaviors for good, Sage.

Linn, R. L. \& Slinde, J. A. 1977. The determination of the significance of change between pre-and posttesting periods. Review of Educational Research, 47, 121-150.

Lock, C. A. \& Kaner, E. F. 2000. Use of marketing to disseminate brief alcohol intervention to general practitioners: promoting health care interventions to health promoters. Journal of evaluation in clinical practice, 6, 345-357.

Luca, N. R. \& Suggs, L. S. 2013. Theory and Model Use in Social Marketing Health Interventions. Journal of Health Communication, 18, 20-40.

Maibach, E. 1993. Social marketing for the environment: using information campaigns to promote environmental awareness and behavior change. Health promotion international, 8, 209-224.

Mainsbridge, C. P., Cooley, D., Fraser, S. P. \& Pedersen, S. J. 2016. A workplace intervention designed to interrupt prolonged occupational sitting: Self-reported perceptions of health from a cohort of desk-based employees over 26 weeks. International Journal of Workplace Health Management, 9, 221-237.

Manning, M. 2009. The effects of subjective norms on behaviour in the theory of planned behaviour: A meta-analysis. British journal of social psychology, 48, 649-705.

McDermott, L., Stead, M. \& Hastings, G. 2005. What is and what is not social marketing: the challenge of reviewing the evidence. Journal of Marketing Management, 21, 545-553.

Michie, S., Johnston, M., Francis, J., Hardeman, W. \& Eccles, M. 2008. From theory to intervention: mapping theoretically derived behavioural determinants to behaviour change techniques. Applied Psychology, 57, 660-680.

Mitchell, T. R. \& James, L. R. 2001. Building Better Theory: Time and the Specification of When Things Happen. The Academy of Management Review, 26, 530-547.

Napier, M. A., Brown, B. B., Werner, C. M. \& Gallimore, J. 2011. Walking to school: Community design and child and parent barriers. Journal of Environmental Psychology, 31, 45-51.

Pang, B., Kubacki, K. \& Rundle-Thiele, S. 2017. Promoting active travel to school: a systematic review (2010-2016). BMC public health, 17, 638.

Perugini, M. \& Conner, M. 2000. Predicting and understanding behavioral volitions: The interplay between goals and behaviors. European Journal of Social Psychology, 30, 705-731. 
Pitariu, A. H. \& Ployhart, R. E. 2010. Explaining change: Theorizing and testing dynamic mediated longitudinal relationships. Journal of Management, 36, 405-429.

Plotnikoff, R. C., Lippke, S., Courneya, K., Birkett, N. \& Sigal, R. 2010. Physical activity and diabetes: An application of the theory of planned behaviour to explain physical activity for Type 1 and Type 2 diabetes in an adult population sample. Psychology and Health, 25, 7-23.

Ployhart, R. E. \& Kim, Y. 2013. Dynamic longitudinal growth modeling.

Ployhart, R. E. \& Vandenberg, R. J. 2010. Longitudinal research: The theory, design, and analysis of change. Journal of Management, 36, 94-120.

Prestwich, A., Sniehotta, F. F., Whittington, C., Dombrowski, S. U., Rogers, L. \& Michie, S. 2014. Does theory influence the effectiveness of health behavior interventions? Metaanalysis. Health Psychology, 33, 465.

Rhodes, R. E. \& Courneya, K. S. 2003. Investigating multiple components of attitude, subjective norm, and perceived control: An examination of the theory of planned behaviour in the exercise domain. British Journal of Social Psychology, 42, 129-146.

Rogosa, D., Brandt, D. \& Zimowski, M. 1982. A growth curve approach to the measurement of change. Psychological Bulletin, 92, 726-748.

Rogosa, D. \& Willett, J. 1983. Demonstrating the reliability the difference score in the measurement of change. Journal of Educational Measurement, 20, 335-343.

Rundle-Thiele, S., Russell-Bennett, R., Leo, C. \& Dietrich, T. 2013. Moderating teen drinking: combining social marketing and education. Health Education, 113, 392-406.

Samuels, S. E. 1993. Project LEAN--lessons learned from a national social marketing campaign. Public Health Reports, 108, 45.

Sarafino, E. P. 1996. Principles of behavior change: Understanding behavior modification techniques, Wiley.

Schuster, L., Kubacki, K. \& Rundle-Thiele, S. 2016. Understanding caregivers' intentions for their child to walk to school: Further application of the theory of planned behavior. Health marketing quarterly, 33, 307-320.

Scott, E. J., Eves, F. F., French, D. P. \& Hoppé, R. 2007. The theory of planned behaviour predicts self-reports of walking, but does not predict step count. British journal of health psychology, 12, 601-620.

Singer, J. D. \& Willett, J. B. 2003. Applied longitudinal data analysis: modeling change and event occurrence, Oxford;New York;, Oxford University Press.

Skår, S., Sniehotta, F. F., Araújo-Soares, V. \& Molloy, G. J. 2008. Prediction of behaviour vs. prediction of behaviour change: The role of motivational moderators in the theory of planned behaviour. Applied Psychology, 57, 609-627.

Smith, W. 1998. Social Marketing: What's the Big Idea? Social Marketing Quarterly, 4, 5-17. 
Stead, M., Gordon, R., Angus, K. \& McDermott, L. 2007. A systematic review of social marketing effectiveness. Health Education, 107, 126-191.

Stritch, J. M. 2017. Minding the time: a critical look at longitudinal design and data analysis in quantitative public management research. Review of Public Personnel Administration, 37, 219-244.

Sundel, M. \& Sundel, S. S. 2004. Behavior change in the human services: Behavioral and cognitive principles and applications, Sage Publications.

Truong, V. \& Dang, N. 2017. Reviewing Research Evidence for Social Marketing: Systematic Literature Reviews. In: KUBACKI, K. \& RUNDLE-THIELE, S. (eds.) Formative Research in Social Marketing: Innovative Methods to Gain Consumer Insights. Singapore: Springer.

Truong, V. \& Hall, C. 2013. Social marketing and tourism: What is the evidence? Social Marketing Quarterly, 1524500413484452.

Truss, A., French, J., Blair-Stevens, C., McVey, D. \& Merritt, R. 2010. Social Marketing and Public Health: Theory and practice. New York: Oxford University Press.

Umeh, K. \& Sharps, M. 2012. Psychological requirements for increased fruit and vegetable intake in young adults. British Food Journal, 114, 1310-1324.

van Breukelen, G. J. 2013. ANCOVA versus CHANGE from baseline in nonrandomized studies: The difference. Multivariate Behavioral Research, 48, 895-922.

Van Rossem, R. \& Meekers, D. 2000. An evaluation of the effectiveness of targeted social marketing to promote adolescent and young adult reproductive health in Cameroon. AIDS Education and Prevention, 12, 383.

Wang, M., Beal, D. J., Chan, D., Newman, D. A., Vancouver, J. B. \& Vandenberg, R. J. 2017. Longitudinal research: A panel discussion on conceptual issues, research design, and statistical techniques. Work, Aging and Retirement, 3, 1-24.

World Health Organization 2010. Global recommendations on physical activity for health. In: PRESS, W. (ed.) WHO Press ed. Geneva: WHO Press.

Xia, Y., Deshpande, S. \& Bonates, T. 2016. Effectiveness of social marketing interventions to promote physical activity among adults: A systematic review. Journal of Physical Activity and Health, 13, 1263-1274. 